\title{
Analysis of Youth Physical Activity Promotion in a Nationally Representative Sample of U.S. Synagogues
}

\author{
David Kahan $^{1}$ (D) Thomas L. McKenzie ${ }^{1}$ (D) Maya Satnick ${ }^{1}$
}

Received: 26 October 2020 / Accepted: 19 April 2021 / Published online: 11 May 2021

(C) The Author(s), under exclusive licence to Springer Nature B.V. 2021

\begin{abstract}
Faith-based organizations are entities recommended to promote and provide healthrelated physical activity to youth. Meanwhile, religious institutions-including synagogues-typically use diverse media, including websites, bulletins/newsletters, and calendars to inform current and potential members about both general (e.g., theological) and specific practical messages (e.g., about the occurrence of services, meetings, and programs). Given the historical role synagogue centers played in the earlyto mid-twentieth century in providing members recreational and sport programming, we were interested to know what physical activities synagogues currently advertise through the aforementioned media. From January through May 2019, we completed a line-by-line analysis of the public websites of a large nationally representative sample of synagogues ( $n=1383$ sites from 337 U.S. cities in 39 states) to assess content (including links to bulletins/newsletters and calendars) related to child and adolescent physical activity. Only $35.4 \%$ of the sampled websites used these media to mention that their synagogue provided even a single physical activity program/ event. Thus, most synagogues either (a) did not provide physical activity programs for children and adolescents, or (b) neglected to use online platforms to promote engagement in them. We found 938 distinct programs/events and 1667 specific activities across synagogue websites that mentioned at least one physical activity. Programs by type and proportion (i.e., percentage of programs overall) included youth group (39.1\%), preschool $(26.9 \%)$, youth worship $(18.0 \%)$, and youth education $(16.0 \%)$. We situate our findings by explicating past and current functions of synagogues related to the provision of youth programming. Future research should examine the beliefs that synagogue rabbis and media gatekeepers hold toward physical activity in general and youth physical activity specifically. Youths should also be queried as to what role synagogue programming can/should play in promoting/ providing and accommodating their physical activity needs and preferences.
\end{abstract}

Keywords Physical activity $\cdot$ Synagogues $\cdot$ Communication $\cdot$ Religion $\cdot$ Website content 


\section{Introduction}

Children and adolescents aged 6-17 years should engage in $60 \mathrm{~min} /$ day of moderate-to-vigorous physical activity (MVPA) (Piercy et al. 2018). Adequate levels of physical activity are associated with improved bone health, weight status, cardiorespiratory and muscular fitness, cardiometabolic health, and cognition, and reduced risk of depression in this age group (Piercy et al. 2018). Despite numerous opportunities and venues for youth to be physically active (e.g., organized sports, active play, active transportation, family and peers, schools, parks, playgrounds, and other community settings), only slightly more than $25 \%$ of U.S. children and adolescents currently meet physical activity guidelines (U.S. Department of Health and Human Services 2020).

Logically, Jewish youth are subsumed in this figure. However, as Jewish community surveys conducted in the U.S. do not typically inquire about health behaviors, there is scant evidence for understanding the scope and severity of physical inactivity and its concomitant morbidities among this segment of the Jewish population. In Chicago, IL, results of two surveys-one conducted in the West Rogers Park and Peterson Park neighborhoods and the other in five Jewish day schools-revealed that among children aged 2-12 years, 51\% reported being active for at least $60 \mathrm{~min} /$ day (Benjamins 2010), while children aged 10-13 years averaged 4 days/week of MVPA, which is 3 days fewer than recommended (Benjamins 2012). Insufficient levels of physical activity in childhood are associated with overweight/obesity (Piercy et al. 2018). Nagel (2008) claimed that the prevalence of pediatric obesity "has reached critical proportions" in the U.S. Orthodox Jewish community, although no data were cited. In the previously cited studies of Jewish youth's health conducted in Chicago, overweight/obesity was found in $54 \%$ and $30 \%$ of the younger and older children, respectively (Benjamins 2010, 2012). In contrast, a national study of Israeli adolescents aged 11-19 years found $50 \%$ and $17 \%$ of Jewish youth were insufficiently physically active and overweight/obese, respectively (Kaluski et al. 2008).

Although not enough is known about the physical activity levels of U.S. Jewish youth, promoting physical activity within this population segment is nonetheless essential for preventive health purposes. Given the low levels of youth physical activity in multiple contexts (e.g., active transportation, school, community) (Aubert et al. 2018), other societal sectors need to participate in physical activity promotion. Indeed, the National Physical Activity Plan (NPAP Alliance 2016) specifically included faith-based institutions and settings among its nine sectors for increasing physical activity levels among Americans. Although there is little empirical evidence for Jewish institutions in this regard, we posit that a latent potential for physical activity promotion exists within such institutions for promoting and providing physical activity programming to affiliated youth.

Before presenting the purpose of our study, which specifically sought to understand how synagogues promoted physical activity to their youth, we first develop a justification for synagogues as loci for physical activity promotion by explicating physical activity (a) hermeneutically from Biblical to present-day texts 
and rabbinic authorities, and (b) sociologically across the past century of Jewish American history as it pertains to Jewish institutions' role in positive youth development.

\section{Exegesis of Physical Activity}

Various forms of physical activity are specifically mentioned in the Tanakh. Searching the Complete Jewish Bible (biblegateway.com), the word(s) "archer/shooting" is found 20 times, "riding" (a chariot, horse, or mule) is found 17 times, and "wrestle/wrestling" is found three times. Including Tanakh and Talmudic verses, Rosner and Weg (1989) identified citations to running (20 times), ball playing (9 times), dancing (8 times), walking (7 times), and swimming (5 times) that they specifically ascribed to exercise.

Allusions to these terms in the Tanakh reflect the natural habitus of Hebrews/ early Jews who primarily led a nomadic life in an agrarian society prior to settling ancient Israel. There they built cities yet had to remain fit for martial preparedness. In Talmudic times, however, rabbis weighed in on physical activity as it related to a conquering alien culture's Hellenizing influence, prevailing medical wisdom, and preserving the keeping of Sabbath and festival laws. To wit, Rosner and Weg (1989) cited Talmudic verses in which rabbis advocated spending one third of the day walking and touted an average person's ability to walk 40 miles in a day, yet also proscribed running on the Sabbath in most circumstances and alternately banned/permitted ball playing on the Sabbath and festivals.

The Rambam (1135-1204) modernized conceptions of physical activity by bringing to bear the confluence of his knowledge as both a physician and rabbinic scholar in authoring multiple volumes that meshed human behavior in physical and spiritual terms. In the Mishneh Torah, Medical Aphorisms, and Regimen of Health, Rambam wrote about exercise in terms commonly accepted in the sports medicine community today: He defined and differentiated exercise by intensity, prescribed warmup/ cooldown phases, and discussed the need to exercise throughout one's lifetime and the health benefits thereof (Rosner and Weg 1989). Bos (1994) mentioned activities the Rambam specified by name including gymnastics, ball games (described as what today would be called "keep-away"), wrestling, boxing, and arm and breathing exercises. From a religious viewpoint he ruled against performing vigorous (i.e., leads to fatigue and perspiration) exercise on the Sabbath because it is curative and healing in the absence of a life-threatening illness (Rosner and Weg 1989). Overall, he viewed attaining a healthy body as a service to Ha-Shem (i.e., a means to an end) allowing one to achieve intellectual vigor and moral virtue (Bos 1994). This viewpoint supports the dual meaning of "and you shall take very good care of your body" (Deuteronomy 4:15), which has been interpreted as an exhortation to health promotion and a reminder to look after one's soul for demonstrating fealty to Ha-Shem's Covenant (Weingarten 2007).

Gurock (2005) considered the Middle Ages a "time-out" for Judaism's problems with sports (i.e., a form of physical activity) because it was impossible for Jews of the time to assimilate/integrate into non-Jewish societies that were openly 
hostile toward them. Centuries later, in the Shulchan Aruch (Rabbi Joseph Karo) and HaMapah (Rabbi Moshe Isserles), parameters were set for exercise, jumping and running, walking, and ball playing on the Sabbath and festivals (Rosner and Weg 1989). In the ensuing centuries, additional rabbis ruled on ball playing, which was popular at the time with Jewish children and adults living in Europe; dealing with principles such as muktsah, mitoch, and eruv, they on balance permitted ball playing conditionally but deemed it antithetical to the spirit of the Sabbath and festivals (Berman 2000).

In more contemporary times, physical activity has been weighed against Torah study in that bitul Torah (i.e., wasting time when one could be learning) is committed if the former preempts the latter (Kahan 2002). Nonetheless, Kaufman (2018) related a story about the Chofetz Chaim (1838-1933) who chastised the yeshiva bachurim who studied excessively:

Do not learn much more than you need to! The individual must take care of his body so that he not weaken and become ill. ... He should walk in the late afternoon or early evening. ... And when it is feasible, he should swim in the river to strengthen his body. (p. 180)

Kaufman (2018) reflected that he and his yeshiva friends in their youth were strong and fit, which they deemed requisite for doing mitzvot and serving Ha-Shem, and lamented that today's yeshiva students in Israel generally do not lead an active lifestyle. Kaufman (2018), as well, cited nine notable rebbeim (e.g., Brisker Rav) and their associated past and current physical activity/exercise preferences, which included baseball, brisk walking, swimming, push-ups, running, and skipping rope.

In his kabbalistic book Orot, Rabbi Abraham Kook (1865-1935), first chief rabbi of Jerusalem, devoted a chapter to his views on physical exercise. He essentially equated secular youth with those studying Torah when he wrote "if youths sport to strengthen their physical ability and spirits for the sake of the nation's strength at large, this holy work raises up the Shekhinah" (Kook and Naor 1993, p. 189). Interpretations of this phrasing and the overall chapter suggested that it (a) was to be taken in temporal context when a Zionist identity needed to be forged and literally physically protected under the British Palestinian Mandate; and (b) looked forward to the future physical struggle to establish the State of Israel (Kook and Naor 1993).

It appears, on balance, that Jewish texts throughout the ages and their authors were aware of Jews' participation in physical activity and supported it-even promoted it-as a corporeal expression of faith and religious desire to attain health. Indeed, Orthodox scholars today continue to clarify the permissibility of exercise and playing sport on the Sabbath and festivals (Berman 2000; Sukenik 2010), while others - at least in Israel-report an increase in Orthodox Jewish adults' physical activity participation (Peles et al. 2018). With general support-albeit mostly from Orthodox branches of Judaism-in the literature for physical activity, questions about who should be physically active, when physical activity can be performed, which physical activities are best/most popular, and why physical activity is important have been answered. Yet who is responsible for promoting/providing physical activity to Jews - particularly youth who are the focus of our study - and where that might occur are not readily apparent. It is to these questions that we next turn. 


\section{Jewish Institutional Support of Physical Activity}

A premise of this section is that physical activity promotion among various Jewish institutions only reaches Jewish youth who affiliate with them. There are currently 1.6 million U.S. youth being raised Jewish (Tighe et al. 2019), and sizable numbers attend formal (e.g., day school, synagogue religious school) and informal (e.g., Jewish activities, youth group, summer camp) Jewish education programs (Kotler-Berkowitz 2005). Therefore, these institutions are ostensibly positioned/responsible for promoting/providing physical activity to Jewish youth.

Eisen (1999) explained that the rise of places and spaces for young Jews to participate in physical activity reflected dual processes of ethnic succession and parallel institutions. In the former, immigrant Jews in the U.S. supplanted other longer-standing ethnic groups' places in various niches including sports; while in the latter, organizations such as the Young Men's (Women's) Hebrew Associations (YM(W)HA) formed because Jews were effectively barred entry into nonJewish physical activity venues. Jewish girls, particularly, also had to overcome co-religionist male hegemony enacted by YMHAs whose policies and practices sidelined or diminished equitable participation in physical culture (Borish 1999). Nonetheless, YWHAs eventually offered Jewish girls a diverse palette of activities, classes, and programs that included badminton, basketball, bicycling, bowling, gymnastics, swimming, tennis, track and field, and volleyball (Borish 1999). The YM(W)HA movement of the late nineteenth/early twentieth century evolved into the Jewish Community Center (JCC) movement of the 1950s with the waning influence of synagogue centers and suburbanization of the U.S. Jewish population. JCCs espoused a modified version of the shul-with-a-pool philosophy associated with synagogue centers (Gurock 2005):

They projected that ideally such classes could be entry point [s] into the Jewish community $\ldots$ in a safe, non-threatening way [for] families who were not yet ready to join a synagogue or perform Jewish rituals at home. For them, evoking their own "from play to stay" scenario, if a secular Jew who is not observant chooses to spend their time with other Jews, hopefully it will lead to other Jewish activities. (p. 176)

Many JCCs opened late on Saturday (i.e., early afternoon) to accommodate synagogue attendance and offered informal recreational programming on the Sabbath (Gurock 2005). Schoenfeld (2020) showed that today's urban JCCs exist in proximity to a patchwork array of Jewish institutions within walking distance and thus reduce the need for synagogues to provide for their congregants' recreational needs. Additionally, JCCs attract 30,000 and 100,000 youth to their early childhood programs and summer camps, respectively (Nussbaum Cohen 2020). Even during the COVID-19 pandemic some JCCs have retained youth summer camp enrollment by entering into innovative place/space partnerships with Reform/ Conservative synagogues (Nussbaum Cohen 2020).

In addition to JCC camps, there are many other denominational and independent Jewish camps available. Jewish camps were once regarded as venues 
for purposefully developing ethnic pride through physical activities collectively termed "muscular Judaism" (Mykoff 2009), and there is high parental agreement $(89 \%)$ that current Jewish day camps are good or excellent at sports (Samuels 2018). Yet detailed empirical data about physical activity programming in these settings is generally lacking. For example, the Foundation for Jewish Camp (FJC 2018a) dedicated only one paragraph to programming (listing seven physical activities) in its 22-page day camp census report. In an ethnography of 20 Jewish residential camps across the U.S., Sales and Saxe (2004) variously and briefly mentioned "sports," "dance," "soccer," "swimming," and "gymnastics." Similarly, for Jewish day camps, Arian (2018) acknowledged camp directors' expressed need of basic facilities for putting on swimming and sports programming; however, he glossed over or omitted specific information about physical activity programming in profiling eight camps. An encouraging development, however, comes from an evaluation of the Specialty Camps Incubator, launched by the FJC with a $\$ 10$ million investment from the Jim Joseph Foundation. Five new Jewish specialty camps were created to attract Jewish teens who were not attending other Jewish camps. Irie et al. (2014) reported that three of the five camps provided robust physical activity opportunities and programs: (a) Adamah (multi-week treks in the mountains, which include backpacking, caving, hiking, kayaking, mountain climbing, and rafting); (b) Ramah Outdoor Adventure (outdoor excursions, which include hiking, horseback riding, mountain biking, rafting, and rock climbing); and (c) 6 Points Sports Academy (4 h daily of intensive sport training in one of nine sport majors and electives in four additional physical activity options). The camps drew and retained campers specifically due to the specialties offered (76\% camper agreement), improved campers' skill levels in those specialties (78\% camper agreement), and were associated with successive increases in synagogue or local Jewish community involvement based on years of attendance (i.e., $41 \%$ for one summer to $62 \%$ for three summers) (Irie et al. 2014).

Despite their potential, the impact of JCCs and Jewish summer camps on youth physical activity is limited because their schedules preclude extended contact time on a daily and/or annual basis. Jewish day schools, in contrast, are in session for approximately half a year and serve more children, and students can attend them from preschool through high school. (In the most recent AVI CHAI Foundation census, over 292,000 students were enrolled in U.S. Jewish day schools [Besser 2020].) Indeed, the Centers for Disease Control and Prevention (2013) charged schools with enacting a comprehensive school physical activity plan (CSPAP) whereby school policies and practices afford students opportunities to participate in high-quality physical education, physical activity during the day (e.g., active classrooms, recess), and before- and after-school physical activity (e.g., active transportation, intramural sport, interscholastic sport). Unfortunately, day schools do not demonstrate a track record suggesting they are committed to providing quality physical education and extracurricular physical activity experiences. For example, two Chicago day schools that participated in a CSPAP intervention used moneys dedicated to improving physical education to purchase basic equipment and access to an external (i.e., JCC) provider (Benjamins and Whitman 2010). (Some day schools and JCCs are adjacent—such as the Scheck Hillel Community School and Michael-Ann Russell JCC 
in South Florida - which would explain this synergy; however, exact figures have not been published.) Partlan (2017) found that New York City Haredi yeshivas did not use public and private funding on secular education (including physical education). Although sports are offered in Jewish day schools, interscholastic sports and intramural physical activity programs were found to be generally under-promoted, particularly in Haredi schools (Kahan et al. 2020). This is disappointing, because the existence of the National Jewish Sports Hall of Fame and Museum (Commack, NY) and the International Jewish Sports Hall of Fame (Netanya, Israel), and the publication of books about the history and biographies of Jewish athletes and sport events (e.g., Siegman 2020; Wechsler 2008) suggest that sports holds salience to some people in modern Jewish society. Additionally, Gurock (2005) depicted tensions within the Orthodox community over the primacy of Torah education versus sport and between Orthodox and non-Orthodox day schools over co-participation in the same sports leagues due to divergent levels of observance.

Unlike the previously profiled Jewish institutions, synagogues frequently offer both formal and informal educational opportunities to their youth congregants in a variety of formats such as preschool, supplementary religious school, camps, worship services, and youth groups. Benjamins (2012) suggested that synagogues should play a greater role in promoting physical activity to adolescents: “... perhaps it would be worthwhile for synagogues to incorporate health-related programs or structures ... such as wellness ministries" (p. 595). Her exhortation postdatesby roughly a century - a time in Jewish American history when synagogue centers flourished and functioned as emporia of social services that included those intentionally catering to congregants' health and wellness needs (Kaufman 1999). Rabbi Mordechai Kaplan (1881-1983) is generally credited with conceiving the synagogue center, which grew out of the $\mathrm{YM}(\mathrm{W}) \mathrm{HAs}$ progressively folding in religious services to their already strong recreational components (Kaufman 1999). Kaplan saw bringing Jews together in social settings versus trying to attract them with religious services as an antidote to disaffection from traditional synagogues (Karp 1987). Kaplan envisioned synagogue centers providing "recreational facilities such as gymnasia, showers, bowling alleys, pool tables and game rooms" (Karp 1987, p. 19). A post-WWI synagogue building boom resulted in synagogue centers becoming an amalgam of sacred and secular spaces replete with gymnasia, dance halls, and swimming pools. Yet during this boom some synagogue rabbis lamented that the centers did not achieve the desired effect of enhanced interest in religious activities and had effectively secularized the synagogue (Kaufman 1999). Nonetheless, all three major branches of Judaism's synagogue centers highlighted their recreational activities and amenities (Silverstein 1994; Wertheimer 1987a). For example, the Brooklyn Jewish Center (https://www.brooklynjewishcenter.org/) located in Crown Heights was established in 1920 and continues today. According to an edition of its 1933 review, members could enjoy "the gymnasium ...[which] activities comprise swimming, basketball, handball, volley ball, calisthenics" (Dash Moore 1987, p. 306). Synagogue centers continued to appeal to second-generation U.S. Jews postWWII and were deemed "crucial institutions in Jewish life" (Wertheimer 1987b, p. 126). They were attractive to suburban, less religious Jewish communities' members who more easily comingled with non-Jewish neighbors yet wanted their Baby 
Boomer generation children to retain a Jewish identity. This incarnation of the synagogue center continued to offer a wide range of social and recreational programs including dances and sport programs (Wertheimer 1987b). The advent and rise of Jewish camps and JCCs in the 1950s and 1960s obviated the need for synagogues to be all things to all people relative to youth and family recreation. Yet vestiges of these eras are seen in modern times: $15 \%$ and $4 \%$ of Conservative synagogues have a gym and pool, respectively (Wertheimer 1996), and 2\% and 6\% of Reform and Conservative synagogues, respectively, reported offering team sports, fitness activities, or exercise programs (Cohen et al. 2011).

\section{Overview and Purpose of the Study}

Although the "heyday" of synagogue centers providing physical activity options to their members has passed, continuing high levels of physical inactivity among youth necessitate alternative societal responses that could once more incorporate the synagogue. According to the National Physical Activity Plan (NPAP Alliance 2016), faith-based organizations should "create an environment supportive of physical activity by delivering evidence-based physical activity messaging and programs that are consistent with the faith community's religious beliefs" (Strategy 1-Tactic 4). Systematic reviews of faith-based and faith-placed physical activity program interventions generally demonstrate improvements in physical activity among primarily adult, non-Jewish participants (Bopp et al. 2012; Tristão Parra et al. 2017).

Investigations of youth physical activity in Jewish synagogue settings have not been conducted. Moreover, the manner by which physical activity is promoted on the websites of religious institutions, in general, remains relatively unknown even though a recent literature review reported that the most frequently researched media channel for messaging physical activity was websites (36\%) (Bergeron et al. 2019). In addition to the information on individual websites, the calendars and bulletins/ newsletters of religious organizations could present other channels for messaging relevant physical activity content. In this regard, an analysis of the websites of 252 Reform Jewish congregations indicated that $74 \%$ of them contained a temple newsletter and 92\% provided a temple calendar (Frost and Youngblood 2014). Unfortunately, Frost and Youngblood (2014) did not study the content of these additional sources specifically related to physical activity promotion. By focusing on websites, we can examine the promotion of physical activity relative to synagogues' efforts utilizing this platform. We also contend-albeit with limitations-that institutions' website promotion serves as a proxy for understanding "generally" their actual provision of physical activity or attitudes toward it (McKenzie 2019). By extension, there may be compelling reasons why synagogues do not promote any physical activity on websites, which may include not having any programming to advertise; relegating the advertising of such programming to offline channels in favor of more traditionally germane content; lacking technical proficiency, financial means, and time to update web content; or some combination thereof. Nonetheless, we state up front that we blurred the distinction between promotion (i.e., websites) and provision 
in this paper, which can only be proved by ground truthing, which was beyond the scope and resources of the study.

Subsequently, with such little information on the content of the websites of U.S. synagogues relative to physical activity promotion, the purpose of our study was to survey (quantify and describe) the messaging of youth physical activity programs and events on synagogue websites, including calendars and bulletins/newsletters. The results of our endeavor can be used by synagogues and their companion and parent Jewish stakeholder organizations for calibrating the amount and types of physical activity promotion/provision synagogues engage.

\section{Method}

\section{Sample Generation}

A sampling frame composed of U.S. Humanistic, Reconstructionist, Reform, Conservative, and Orthodox synagogues was identified from the online directory of each denomination. We did not include Renewal synagogues (https://aleph.org/ directory; 37 U.S. synagogues, 29 with websites) due to their scarcity relative to other denominations. For Orthodox synagogues, we referred to the Union of Orthodox Jewish Congregations of America directory (https://www.ou.org/synagoguefinder/) because it was the largest by several hundred compared to Agudath Israel of America (no publicly accessible central directory) and National Council of Young Israel (https://youngisrael.shulcloud.com/shul-web-list.html; 95 synagogues with websites). We also excluded Chabad-Lubavitch synagogues (https://www.chabad. org/centers/default_cdo/country/USA/jewish/Chabad-Lubavitch.htm) because their website interfaces were constructed in ways that necessitated a less systematic search protocol, and finding data was exceedingly laborious.

A total of 2256 synagogues were listed, and we used the Creative Research Systems' sample size calculator (https://www.surveysystem.com/sscalc.htm), with parameters of a $95 \%$ confidence level and a $\pm 3 \%$ confidence interval, to identify the requisite number of synagogues to be sampled by denomination. We then generated random samples for each denomination (Humanistic, $n=24$; Reconstructionist, $n=83$; Reform, $n=462$; Conservative, $n=368$; and Orthodox, $n=446$ ) for a grand total of 1383 synagogues (i.e., $61.3 \%$ of all listed synagogues). (When we encountered a randomly selected synagogue that did not have a website, a randomly selected replacement synagogue was used.)

\section{Data Extraction}

Between January and May 2019, the websites of these synagogues were searched line-by-line for the mention of youth physical activity programming that was either general or date/time-specific. Multiple sources were searched: (a) webpages including seasonal program guide links, (b) posted synagogue calendars (3 months both before and after the search month), and (c) posted synagogue bulletin/newsletters 
(most current issue). After initial screening, 894 (64.6\%) of the synagogue websites were excluded because they provided no mention of physical activity programming on any of the three sources. The remaining 489 synagogue websites thus comprised the analytic sample, with $445(91.0 \%)$ providing access to a calendar and 261 $(53.5 \%)$ providing access to a bulletin/newsletter. Overall, 50.3\%, 43.6\%, and $6.1 \%$ of the websites provided three, two, and one source(s) to search for physical activity content.

The data were extracted by three individuals - the senior author, who had extensive experience assessing website content, and two students that he trained. Trainees were certified to independently code websites only after they achieved an $80 \%$ interrater reliability for each physical activity type for a subsample of five synagogues.

Any physical activity programming with a primary target audience that included children from birth through high school age was assessed, and those programs were classified into one of four categories: (a) youth education (i.e., religious school, Hebrew school, Bar Mitzvah training classes, camps held on-site); (b) youth worship (i.e., programming in conjunction with weekly Sabbath and any Jewish holiday/ ritual observances); (c) youth group (i.e., programming in conjunction with social groups, synagogue-sponsored sports leagues, synagogue-sponsored after-school programs); and (d) synagogue preschool (i.e., preschool-age general physical education curriculum, after-preschool programs, parent-and-child programs, preschoolsponsored camps held on-site).

Coding each program category included identifying the number of unique programs, the number of unique physical activities listed for each program, and the names of specific activities. For example, a synagogue website may have listed a youth group program that included physical activity (i.e., one program), which involved both laser tag and mini-golf (i.e., two physical activities for that program). A student coder hand-tallied the frequencies of names of physical activities, and these were checked by the senior author. Subcategories were created a priori to distinguish groupings by youth worship (birth-8 years vs. older) and school level (elementary or lower, middle, high, and mixed).

\section{Analysis}

Frequencies, proportions, medians, and interquartile ranges (IQR) for each of the four program categories and the physical activity types were calculated. (An interquartile range is a measure of variability used when data are not normally distributed and is the difference between the largest and smallest values in the middle $50 \%$ of a set of data). 


\section{Results}

\section{Sample}

The 1383 sampled synagogues represented 337 cities and 39 states. By state, the largest proportions were in New York (18.6\%), California (12.7\%), New Jersey (12.3\%), Florida (6.5\%), and Pennsylvania (5.9\%). Four hundred and eightynine $(35.4 \%)$ of the synagogues mentioned at least one youth physical activity program, and all five denominations were represented: Humanistic $(0.4 \%)$, Reconstructionist (8.4\%), Reform (27.0\%), Conservative (45.4\%), and Orthodox $(18.8 \%)$.

\section{Data Sources}

Of the 489 synagogues providing physical activity program information on their websites, 460 (94.1\%) used webpages, 130 (49.8\%) used bulletins/newsletters, and $115(25.8 \%)$ used calendars. Overall, 63.2\% of the websites provided the information via a single source, $29.4 \%$ used two, and $7.4 \%$ used all three sources.

\section{Physical Activity Programs by Category}

The following results are from the analysis of the 489 websites that identified having at least one physical activity program (i.e., $35.4 \%$ of total website sample). They are presented separately for each of the four overarching program categories: youth education, youth worship, youth groups, and synagogue preschools.

\section{Youth Education}

The synagogue websites mentioning physical activity in their youth education programming $(n=146,30.0 \%)$ identified $1.0 \pm 0.0$ (median \pm IQR) physical activity programs for each of the school and camp subcategories. Combined, 150 separate programs and 257 specific physical activities were identified on those websites (Table 1). While most programs were in synagogue schools $(75.3 \%)$, the physical activities identified were relatively more balanced between school (56.4\%) and camping (43.6\%) programs (Table 1). Table 1 lists the five most frequently listed physical activities in the two settings, with dance, martial arts, and yoga appearing for both locations. Some of the more frequently occurring activities were prominent in a single setting (e.g., movement and Israeli dance in synagogue schools; sports and swimming in synagogue camps) (Table 1).

\section{Youth Worship}

The synagogue websites mentioning physical activity as part of youth worship $(n=169,33.9 \%)$ identified $1.0 \pm 0.0$ (median $\pm \mathrm{IQR})$ physical activity programs, 
Table 1 Youth education physical activity (PA) programs by category and physical activity type

\begin{tabular}{llcc}
\hline Category activity & Programs $(n)$ & PA types $(n)$ & PA types $(\%)$ \\
\hline Overall & 150 & 257 & \\
Synagogue schools & 113 & 145 & \\
Dance & & 41 & 28.3 \\
Movement & 32 & 22.1 \\
Israeli dance & 18 & 12.4 \\
Yoga & 11 & 7.6 \\
Martial arts & & 6 & 4.1 \\
All others & & 37 & 25.5 \\
Synagogue camps & 37 & 112 & \\
Sports & & 25 & 22.3 \\
Swimming & & 17 & 15.2 \\
Dance & & 10 & 8.9 \\
Martial arts, yoga & & 5 (each) & 8.9 \\
All others & & 50 & 44.6 \\
\hline
\end{tabular}

Programs refers to the mention of a general or specific (i.e., date/ time certain) program that included PA. PA types refers to the total number/percentage across programs or specific PAs (e.g., sports and yoga offered at synagogue winter camp)

Table 2 Youth worship physical activity (PA) programs by age and religious observance

\begin{tabular}{llll}
\hline $\begin{array}{l}\text { Age } \\
\text { Holiday }\end{array}$ & Programs $(n)$ & PA types $(n)$ & Top PA type (\%) \\
\hline Overall & 169 & 223 & \\
Younger children & 148 & 193 & Dance (39.4), bounce house (23.3), movement (16.1) \\
Sabbath & & 122 & \\
Purim & 54 & \\
All other holidays & & 17 & \\
Synagogue camps & 21 & 30 & Dance (16.7), bounce house (10.0), apple picking, \\
Sabbath & & 11 & obstacle course, scavenger hunt (6.7 each) \\
Purim & & 9 & \\
All other holidays & & & \\
\hline
\end{tabular}

Programs refers to mention of a general or specific (i.e., date/time certain) program that included PA. PA types refers to the total number mentioned across programs/holidays (e.g., dance mentioned as part of a Sabbath younger children's service $=1 \mathrm{PA}$ )

with most of them (87.6\%) catering to younger children. Combined, there were 169 separate programs with 223 specific physical activities associated with them (Table 2). Specific physical activities were identified mostly in conjunction with Sabbath (59.6\%) and Purim (28.7\%) rather than for 11 other holidays and observances (Table 2). Overall, dance was mentioned most frequently (Table 2), with 
dance and bounce house activities particularly prevalent as part of programs for younger children on the Sabbath $(56.6 \%)$ and Purim $(77.8 \%)$, respectively.

\section{Youth Groups}

The synagogue websites mentioning physical activity among youth groups $(n=267,54.8 \%$ ) identified $1.0 \pm 1.0$ (median $\pm \mathrm{IQR}$ ) programs each for middle school-, high school-, and mixed school-age youths, $1.5 \pm 1.8$ (median \pm IQR)

Table 3 Youth group physical activity (PA) by school/program levels and activity type

\begin{tabular}{|c|c|c|c|}
\hline School-level activity & Programs $(n)$ & PA types $(n)$ & PA types (\%) \\
\hline Overall & 367 & 633 & \\
\hline Elementary school & 48 & 97 & \\
\hline Bowling & & 16 & 16.5 \\
\hline Ice skating, mini golf & & 11 (each) & 22.6 \\
\hline Laser tag, scavenger hunt & & 8 (each) & 16.4 \\
\hline Others & & 43 & 44.3 \\
\hline Middle school & 73 & 122 & \\
\hline Bowling & & 24 & 19.7 \\
\hline Laser tag & & 19 & 15.6 \\
\hline Ice skating & & 12 & 9.8 \\
\hline Sports & & 10 & 8.2 \\
\hline Climbing & & 7 & 5.7 \\
\hline Others & & 50 & 41.0 \\
\hline High school & 95 & 158 & \\
\hline Dance & & 27 & 17.1 \\
\hline Bowling & & 25 & 15.8 \\
\hline Ice skating & & 18 & 8.2 \\
\hline Laser tag, scavenger hunt & & 11 (each) & 14.0 \\
\hline Others & & 66 & 41.8 \\
\hline Mixed school levels & 109 & 200 & \\
\hline Bowling & & 33 & 16.7 \\
\hline Ice skating, scavenger hunt & & 15 (each) & 15.0 \\
\hline Snow sports & & 14 & 7.0 \\
\hline Laser tag & & 13 & 6.5 \\
\hline Others & & 110 & 55.0 \\
\hline After-school and sports programs (all ages) & 42 & 56 & \\
\hline Basketball & & 1515 & 26.8 \\
\hline Soccer & & 8 & 14.3 \\
\hline Baseball, dance, martial arts, swimming & & 4 (each) & 28.6 \\
\hline Others & & 17 & 30.4 \\
\hline
\end{tabular}

Programs refers to mention of a general or specific (i.e., date/time certain) program that included PA. PA types refers to the total number/percentage across programs or specific PAs (e.g., gymnastics and basketball mentioned in a synagogue after-school program $=2$ PA for 1 program) 
programs for elementary school-age youths, and $1.0 \pm 0.3$ (median $\pm \mathrm{IQR}$ ) youth sports programs. Combined, there were 367 separate programs with 633 specific physical activities associated with them (Table 3). More programs and physical activity types were reported for middle school- and high school-age than elementary school-age youth. Bowling, ice skating, and laser tag were mentioned frequently at all levels; however, activity types differed substantially by school level (Table 3).

After-school physical activity and sports programs were mentioned infrequently and were not categorized by school grouping here (Table 3). Of these programs, team sports $(55.4 \%)$ (e.g., basketball, soccer, baseball) were most frequently cited.

\section{Preschools}

The synagogue websites mentioning physical activity in their preschool programs $(n=195,40.0 \%)$ identified $1.0 \pm 2.0$ (median $\pm \mathrm{IQR}$ ) preschool, $2.0 \pm 2.0$

Table 4 Preschool physical activities (PA) by program and activity type

\begin{tabular}{|c|c|c|c|}
\hline Program type activity & Programs $(n)$ & PA types $(n)$ & PA types $(\%)$ \\
\hline Overall & 252 & 574 & \\
\hline School curriculum & 129 & 305 & \\
\hline Movement & & 57 & 18.7 \\
\hline Dance & & 46 & 15.1 \\
\hline Gross motor activity & & 34 & 11.1 \\
\hline Yoga & & 32 & 10.5 \\
\hline Gardening & & 20 & 6.6 \\
\hline Others & & 116 & 38.0 \\
\hline Extracurricular & 63 & 182 & \\
\hline Dance & & 28 & 15.4 \\
\hline Soccer & & 24 & 13.2 \\
\hline Gymnastics, yoga & & 21 (each) & 23.0 \\
\hline Sports & & 20 & 11.0 \\
\hline Others & & 68 & 37.4 \\
\hline Parent-and-child & 60 & 87 & \\
\hline Movement & & 30 & 34.5 \\
\hline Dance & & 17 & 19.5 \\
\hline Gross motor activity & & 8 & 9.2 \\
\hline Gymnastics, yoga & & 7 (each) & 16.1 \\
\hline Others & & 18 & 20.7 \\
\hline
\end{tabular}

Programs refers to mention of a general or specific (i.e., date/time certain) program that included PA. PA types refers to the number/ percentage mentioned across programs or specific PAs (e.g., dance, gross motor activity, and yoga mentioned as part of preschool curriculum $=3$ PA for 1 program) 
(median $\pm \mathrm{IQR})$ extracurricular, and 1.0 \pm 0.0 (median $\pm \mathrm{IQR})$ parent-and-child physical activity programs. Combined, there were 252 separate programs and 574 specific physical activities associated with the preschool programs (Table 4). The majority of preschool programs $(51.2 \%)$ and associated physical activities $(53.1 \%)$ were related to the preschool curriculum, not extracurricular or parentand-child offerings. Numerous physical activities were identified across program types, with dance and yoga among the top five in all three categories (Table 4).

\section{Discussion}

Houses of worship can play a key role in promoting physical activity because they "have unique social systems, environments and physical structures (e.g., fellowship halls), communication channels, policies and practices, and often, health-related goals and supports (i.e., health ministries), which make them particularly conducive to promoting physical activity" (NPAP Alliance 2016, p. 22). Relative to this role, we examined the content of U.S. synagogue websites in order to assess their messaging of physical activity programs targeting children and adolescents.

\section{Absence of Physical Activity Messaging}

We spend considerable time in the next section putting into perspective our findings for websites that mentioned physical activity programming. Yet we were struck by finding that $64.6 \%$ of the sampled websites omitted mention of physical activity programming altogether. To reiterate what was mentioned in the preface to the purpose of our study: There may be several wholly appropriate reasons to explain such omissions that include not having any programming to advertise; relegating the advertising of such programming to offline channels in favor of more traditionally germane content; lacking technical proficiency, financial means, and time to update web content; or some combination. This first reason is most concerning, although it cannot be proven in this study. The introductory tableau of the promotion/provision of physical activity in historical and contemporary Jewish texts and Jewish American society suggests it merits inclusion. Physical activity, however, is frequently a personalistic behavior that perhaps does not readily fit into the primal notion of the synagogue as a kehillah (community). Yet Jewish adolescent boys have been found to prefer sports and action-related activities, and regardless of gender, "as involvement with after school activities increases among Jewish teens, so does their willingness to participate with Jewish-focused activities" (Whitehead-Bust 2010, p. 6). As such, we recommend synagogues take advantage of this trend by providing various age-appropriate and gender-inclusive (as cultural/religious mores permit) physical activity options and promoting them online. We also recognize that website promotion may not directly reach the desired target groupsparticularly teens who primarily use YouTube (85\%), Instagram (72\%), and Snapchat (69\%) online platforms (Anderson and Jiang 2018). Thus, promotion should be tailored to fit these platforms. 


\section{Presence of Physical Activity Messaging}

\section{Youth Education}

Synagogue school physical activities outnumbered those at synagogue camps approximately 3 to 1 . This finding seems counterintuitive. It is possible that parents implicitly expect camps to offer physical activity while they do not for synagogue schools. Thus, synagogues may purposely advertise synagogue schools with such options to further sell them to parents as sources of some physical activity on weekdays after school and Sundays. Meanwhile, synagogue schools provide religious education that supplements what children receive at home, in other synagogue programs, and during informal experiences such as camps. Nationally, over 230,000 children attend about 1700 synagogue schools (Wertheimer 2008), and these have stated goals of developing community, Jewish identity and knowledge, and pro-Jewish behaviors among students. In achieving such goals, synagogue youth educators may incorporate physical activity_particularly that which is connected to Jewish history/tradition. The frequent listings of "dance" generally and Israeli dance specifically expose students to historical-through-modern cultural and religious aspects of Judaism (Ingber 2011). Additionally, these activities along with general "movement" ( $\sim 63 \%$ of all physical activities mentioned) may reflect a focus on the utilization of kinesthetic learning modalities to reinforce the learning of Hebrew language, prayers, etc. A curricular example of such an approach is found in "Hebrew through Movement" (https://www.hebrewthroughmovement.org/), which is being used in various Jewish institutions-including synagogues-to teach non-conversational Hebrew through moving and doing.

Camps were categorized under youth education; synagogues offering camp experiences on-site are likely able to provide lower-cost camping alternatives than nonsynagogue camps, and by being geographically proximal allow campers to return home each day. Nonetheless, the scarcity of messaging about physical activities may have been the result of synagogue camps focusing on programming that did not have a physical activity element (perhaps because of space and facilities) or relying on non-synagogue camps to cater to their youth congregants. Indeed, adequate space for providing aquatic and sport programs has been cited as prerequisite by non-synagogue camp directors (Arian 2018), and only a small percentage of synagogues retain gyms and pools that were most likely built during the synagogue center era (Wertheimer 1996).

Altogether in the U.S., 331 Jewish day and overnight camps serve around 154,000 youths (FJC 2018a, 2018b). The day camps are often specialized, and they offer activities such as gymnastics, soccer, archery, karate, rugby, sports, and dance (FJC 2018a). Overnight camps (about $70 \%$ of the total) have recently reported having a gross revenue of at least $\$ 800,000$ each (FJC 2018b), and this may afford them the ability to provide venues, equipment, and specialists for various sports and activities that synagogues cannot. Additionally, parents may view sports as the purview of non-synagogue camps, as nearly $90 \%$ of 1273 parents surveyed agreed that JCC day camps were good or excellent at sports (Cohen and Melchior 2011). Thus, parents interested in their children participating in sports in camp settings may not consider 
synagogue-based camps; instead they may prefer non-synagogue-based Jewish camps, especially newer specialty camps that emphasize sports (Irie et al. 2014).

\section{Youth Worship}

Physical activity associated with youth worship was mostly mentioned in conjunction with the Sabbath and primarily catered to younger children. This is logical, as (a) the Sabbath occurs weekly and most other observances occur only once annually, and (b) attendance by youths at synagogue worship services in the more liberal denominations of Judaism declines post-bar/bat mitzvah (i.e., during the teen years) (Bryfman 2016).

Dance was the most common physical activity mentioned relative to youth worship, and acute bouts of physical activity_such as those occurring when dancing is part of a worship service-may have beneficial effects on certain cognitive tasks, which include memorization (Donnelly et al. 2016). Pairing physical movements with the utterance of prayers in Hebrew-a second language for most American Jewish children-may enable them to learn the prayers faster. (The "Hebrew through Movement" curriculum previously mentioned recommends that students complete Foundational Level 6 to successfully integrate Hebrew through Movement into prayer learning; https://www.hebrewthroughmovement.org/prayers--blessings. html) Additionally, dance is a Jewish expression of worship; it is mentioned nine times in verses found in Ecclesiastes, Exodus, Jeremiah, Lamentations, Psalms, and Samuel.

After Sabbath, Purim was next most frequently associated with the mention of physical activity, and "bounce houses" (i.e., jumping) were most common. The mentioning of bounce houses was associated with community-wide carnivals, which are a traditional feature of Purim celebrations (Gold 1991). We note, however, that the higher frequency of physical activity mentioned in conjunction with Purim may be due to its celebration in late winter, which coincided with the timing of data collection. We anticipate that other holidays with natural associations to physical activity would be similarly advertised in their respective seasons such as Simchat Torah (autumn), when celebrants dance with the Torah scrolls, and Lag B'Omer (spring), which is often celebrated with outdoor activities at parks.

\section{Youth Groups}

Youth group physical activities were the most frequently messaged category and the only one where activities were found on over $50 \%$ of synagogue websites. By comparison, the other three categories of physical activities were messaged much less frequently, ranging between $30 \%$ (youth education) and $40 \%$ (preschool).

Jewish youth organizations, which focus on sustaining ethnic and religious affiliation among Jews post-bar and -bat mitzvah, were created by the Reform, Conservative, and Orthodox denominations between 1939 and 1951 (Bronner and Clark 2016). Most frequently, they operate under the aegis of a sponsoring synagogue, and they provide an assortment of educational, recreational, and social activities to bring Jewish school-age youths together. Youth group activities are highly valued by 
Jewish teens (Bryfman 2016; Levites and Sayfan 2019) — who often take on a major role in organizing them-and thus may be the category in which synagogue youth and education directors should most focus future programming efforts.

Interestingly, most physical activities in the youth group category were indoor, individual sports that provided low-to-moderate energy expenditure (e.g., bowling, ice skating, laser tag), which contrasts with youth participation patterns that favor outdoor, team sports that require high levels of physical fitness (Physical Activity Council 2019). As synagogues typically have limited physical spaces, fiscal resources, and/or organizational/pedagogical expertise to provide physical activities, they often rely on outside vendors to provide them. Meanwhile, it is important to consider that study data were collected during the winter and early spring months. As many of the synagogues were in areas with continental climates (i.e., noted for extreme seasonal changes), the physical activities for the youth groups were likely planned in consideration of inclement weather.

The number of youth group physical activity programs identified on the websites increased by school level: elementary (13.1\%), middle (19.9\%), and high $(25.9 \%)$ school. This may be associated with older youths (a) identifying and socializing more with peers than family; (b) being less reliant on parents for transportation, chaperoning, and co-participating in events; and (c) having the requisite skills and heightened interest for participating in a wider variety of activities. Additionally, adolescents in high school are in the final years of regularly living in their parents' home and being included under synagogue family-unit membership. Thus, it is possible that synagogue programming is more heavily promoted to them to grow and stabilize their Jewish identities prior to them leaving the family home.

Synagogues often view youth groups as a means for encouraging adolescents to maintain participation in synagogue activities (Bronner and Clark 2016). For example, teens involved in Jewish activities have been reported to have higher scores on all 14 GenNow outcomes (e.g., establish strong friendships, have a sense of pride about being Jewish, have the desire and commitment to be part of the Jewish people now and in the future), which were the result of the Jewish Education Project's survey to understand and engage Jewish teens (Levites and Sayfan 2019). Meanwhile, youth group participation, although acknowledged as enjoyable by Jewish teens, is thought of as falling "somewhere between the obligation of school and freely chosen 'fun' pastimes" (Woocher 2015, p. 4). Subsequently, in order to engage American Jewish teens, it is recommended that synagogues (a) design activities that overflow with laughter, fun, and play; (b) welcome participants' friends regardless of religion and synagogue affiliation; (c) encourage secular activities and not view them as competition; and (d) promote activities that best meet teens' needs versus seeking a higher number of participants in the synagogues' conventional programming (Bryfman 2016).

The "after-school and sports activities" was the least represented type of programming (11.4\%) in the youth group category. These require space, equipment, and specialized instructors that are often not available in synagogues. After-school intramural and interscholastic sport offerings are often also available in non-synagogue settings. Indeed, Jewish teens frequently report community- and school-based sports and physical activities as favorite things to do outside of school on afternoons and 
weekends (Woocher 2015). In this regard, youths with a large network of Jewish friends are more likely to raise a Jewish family as adults and to remain engaged in the Jewish community than those youths without such a network (Cohen and Veinstein 2011). Subsequently, synagogues should continue and potentially increase promoting after-school sports programming-possibly collaborating or co-sponsoring sports programming with JCCs and neighboring synagogues. For example, the National Council of Young Israel Basketball League (https://youngisrael.org/servi ces/) is open to boys and girls in middle school and higher in the New York-New Jersey metro area with teams representing schools and shuls.

\section{Preschool}

Day-care centers and preschools are generally charged with promoting and providing quality physical activity (Goldfield et al. 2012). Meanwhile, many synagogue preschools function semi-autonomously from synagogue and rabbinical oversight, and they typically do not actively recruit students from synagogue membership (Beck 2002). Instead of focusing on knowledge acquisition like primary Jewish day schools, they instill Jewish values in students by infusing rituals and traditions of Sabbath and other holidays into their activities/curricula (Beck 2002). Families with children who attended early childhood Jewish education programs have reported greater ritual observance and involvement in Jewish education during their child's post-preschool years, suggesting that the experience serves as a primary connection to the Jewish community, particularly among interfaith and non-Jewish families (Vogelstein 2008). Synagogue preschools thus occupy an important niche in the lives of young children from a religious standpoint. Preschools also likely play an important role in providing opportunities for children to be physically active. In this regard, the websites of $40 \%$ of the synagogues indicated that their preschools offered at least one physical activity program.

The messaging about preschool physical activity on synagogue websites was primarily about it being part of the school curriculum. This included rhythmic activities such as dance and creative movements, which can help improve sensorimotor synchronization that is important during both routine daily activities and sport activities (Chatzihidiroglou et al. 2018). We have previously commented on the appropriateness of movement for learning Hebrew language and prayers.

Messaging also included extracurricular preschool programs, which primarily were rhythmic activities and sports that were typically offered on-site by an outside vendor. Although competitive sports are not recommended until middle childhood (ages 6-9 years) (Purcell 2005), parent demand often drives them being included for young children even though a single sport program (e.g., soccer) may focus on only a small set of discrete skills. Synagogue preschools that advertise extracurricular physical activity programs employ a shrewd marketing strategy for keeping children on campus for up to several hours after school, which may be appreciated by working parents, and may also generate additional revenue for the preschool.

Parent-and-child programs, a third program type, primarily cater to children aged 2-3 years (i.e., not yet old enough to attend preschools) and their parents. Jewishoriented parent-and-child programs are attractive primarily to new Jewish parents 
who are interested in meeting parents like themselves. Nonetheless, this concept has been largely ignored in early childhood Jewish education (Vogelstein 2008). Thus, it is not surprising that the frequency of messaging of physical activity within parentand-child programs was lowest among the three program types. When mentioned, the programs focused more broadly on activities like those messaged in the preschool curriculum, and few specific activities were identified.

\section{Reflections on Strengths, Limitations, and Future Directions}

While faith-based settings are a recommended resource for promoting and providing health-related physical activity, the current study is unique in its assessment of local site-based media efforts (i.e., via websites, bulletins/newsletters, and calendars) to inform web users about physical activity programs. Synagogues often use diverse media to inform current and potential members about both general theological messages and specific details about services and programs. We relied on media available on publicly accessible websites and therefore could not assess members-only content, nor did we endeavor to access bulletins/newsletters and calendars available only in print form. A strength of the study is that it included a large random selection of Jewish synagogues from across the U.S. and examined multiple media types, which increases the likelihood that what was viewed was a reasonable proxy of the actual physical activity programs offered. Yet we cannot determine participation rates for the events we found. The uptake of physical activity is always a personalistic decision - the best purveyors (whether they be gyms, trainers, houses of worship, etc.) can do is offer programming that resonates with their target audience and hope they participate.

Most (76\%) U.S. Jews attend synagogue religious services a few times per year or less, and $22 \%$ describe themselves as having no religion (Pew Research Center 2013). Therefore, even optimal synagogue promotion of physical activity to youth members would overlook thousands of synagogue non-members and cultural Jews. Information about the likely socioeconomic, and racial and ethnic backgrounds of the Jews who affiliate with these synagogues was not available. It may be that Jews who affiliate with a synagogue that is affiliated with a denominational organization (from where we obtained our sample) - a substantial expense and commitment for a synagogue such that some synagogues drop affiliation-and that updates their websites are on average middle class or upper middle class, and not a particularly vulnerable group to physical inactivity. Indeed, physical activity and other health behaviors are marked by a social gradient, whereby disadvantaged youth engage less than advantaged peers (Ball et al. 2015). Thus, synagogues with a preponderance of financially secure members may not see a need to offer physical activity programming to their youth.

Moreover, the Jews with the greatest health vulnerabilities and lowest socioeconomic status are Jews of non-European descent and Haredi Jews, especially Hasidic Jews (e.g., Peles et al. 2018); synagogues serving this demographic may not have websites with useful information, and they may be difficult to locate in any sampling frame. Interestingly, many people who attend these and other Orthodox synagogues 
walk to synagogue. (Kahan (2007) found increased walking on the Sabbath but no additional walking on the other 6 days.) In our study there were several instances when a synagogue advertised a Tashlich service and invited community members (including children) to walk to the body of water. One day of additional physical activity, however, may be counteracted by increased calorie consumption. Specifically, Rosenberg et al. (2016) found that obese women consumed more calories on the Sabbath than the other days of the week.

We also posit an alternative argument for framing our findings: If a synagogue, that has low salience to youth members, promotes activities they are not interested in, or that they regard as not what they go to synagogue for, they will not go (Bryfman 2016; Levites and Sayfan 2019). By contrast, a synagogue that has high salience to youth members can encourage them to try activities that they may not otherwise engage in, and many will go along with the new activities. Unfortunately, there is no way to practicably know the level of salience youth members hold toward their individual synagogues.

Overall, results showed that synagogues did not optimally use in-house media to promote physical activity programs to their youth membership. As rabbis may exercise ultimate gatekeeping authority over congregational website content, it would be valuable to conduct studies that investigate their attitudes toward physical activity and whether and how they view their synagogues promoting it generally and online. Indeed, Gurock (2005) recounted a time during the synagogue center era when the synagogue rabbi-charged with making the synagogue relevant to youth-was expected to know the latest scores and statistics of sports teams and players, and coordinate, supervise, and participate in various synagogue-run games and outings. During this same time, Yeshiva University (YU) purposely "highlighted the athleticism of its young rabbis and the prowess of its college teams" (Gurock 2005, p. 116). Gurock (2005) further related the beliefs of YU's physical education department chair at that time-Abraham "Doc" Hurwitz-who maintained "that the rabbi or Hebrew school teacher trained in physical education and recreational supervision can be a potent force in dealing with our backsliding youth and returning them to the faith of our fathers" (p. 117).

Additionally, surveying Jewish youth's attitudes toward synagogue provision of physical activity could help identify specific activities that would result in high attendance if they were offered. Synagogues that can seamlessly couple secular and religious components are more likely to resonate with Jewish youth. Jewish teens, in particular, value their free time activities (including sports), yet do not view Jewish activities as voluntary - even those they enjoy — and instead continue with those they feel relate to and reinforce their goals (i.e., value-added dimension) (Bryfman 2016).

It is important to consider that the results were cross-sectional and time-specific (winter, early spring); they might not generalize to other time periods. Following the trajectory of physical activity messaging across the entire Jewish calendar might reveal additional holiday-specific trends. We did not semantically distinguish between general descriptions of physical activity programs and those that were date/ time-specific and thus likely to have occurred. Future studies should make such differentiations. 
Meanwhile, despite the National Physical Activity Plan's inclusion of faith-based organizations (NPAP Alliance 2016), there is still little scientific evidence that faith-based programs contribute significantly to adherents' overall accrual of physical activity. Subsequently, there is a clear need both to expand the evidence base that links faith-based settings generally, and synagogues specifically, to increased physical activity and to assess whether the results are generalizable across different congregational contexts (i.e., urban classification, socioeconomic status, denominational affiliation). Lastly, interventions for increasing promotion of physical activity and its provision to youth in synagogue settings are conspicuously absent in the literature. Synagogue collaborations with other Jewish agencies (e.g., JCCs, day schools, Jewish Federations' community health arms, camps) that present a unified and coordinated approach to enhance the physical activity levels of youth would be especially welcome.

\section{References}

Anderson, Monica, and Jingjing Jiang. 2018. Teens, social media and technology 2018. Washington, DC: Pew Research Center.

Arian, Ramie. 2018. Intentional Jewish day camps: An emerging phenomenon. New York, NY: Foundation for Jewish Camp.

Aubert, Salomé, Joel D. Barnes, Nicolas Aguilar-Farias, Greet Cardon, Chen-Kang. Chang, Christine Delisle Nyström, Yolanda Demetriou, Lowri Edwards, Arunas Emeljanovas, Aleš Gába, Wendy Y. Huang, Izzeldin A.E.. Ibrahim, Jack Jürimäe, Peter T. Katzmarzyk, Agata Korcz, Yeon Soo Kim, Eun-Young. Lee, Marie Löf, Tom Loney, Shawanda A. Morrison, Jorge Mota, John J. Reilly, Blanca Roman-Viñas, Natasha Schranz, John Scriven, Jan Seghers, Thomas Skovgaard, Melody Smith, Martyn Standage, Gregor Starc, Gareth Stratton, Tim Takken, Tuija Tammelin, Chiaki Tanaka, David Thivel, Richard Tyler, Alun Williams, Stephen H.S.. Wong, Pawel Zembura, and Mark S. Tremblay. 2018. Report card grades on the physical activity of children and youth comparing 30 very high human development index countries. Journal of Physical Activity and Health 15 (S2): S298-S314.

Ball, Kylie, Allison Carver, Katherine Downing, Michelle Jackson, and Kerry O'Rourke. 2015. Addressing the social determinants of inequities in physical activity and sedentary behaviours. Health Promotion International 30(S2): ii8-ii19.

Beck, Pearl. 2002. Jewish preschools as gateways to Jewish life: A survey of Jewish preschool parents in three cities. New York, NY: Ukeles Associates Inc.

Benjamins, Maureen R. 2010. Fighting childhood obesity in a Jewish community. In Urban health: Fighting disparities with local data, ed. Steven Whitman, Ami Shah, and Maureen Benjamins, 197-224. New York, NY: Oxford University Press.

Benjamins, Maureen R. 2012. Religious beliefs, diet, and physical activity among Jewish adolescents. Journal for the Scientific Study of Religion 51 (3): 588-597.

Benjamins, Maureen R., and Steven Whitman. 2010. A culturally appropriate school wellness initiative: Results of a 2-year pilot intervention in 2 Jewish schools. Journal of School Health 80 (8): 378-386.

Bergeron, Caroline D., Andrea H. Tanner, Daniela B. Friedman, Yue Zheng, Courtney S. Schrock, Daniel B. Bornstein, Michelle Segar, and Natalie Swift. 2019. Physical activity communication: A scoping review. Health Promotion Practice 20 (3): 344-353.

Berman, Saul J. 2000. Playing ball on Shabbat and Yom Tov. The Edah Journal 1(1). http://www.edah. org/backend/JournalArticle/berman.pdf. Accessed 15 October 2020.

Besser, Mordechai. 2020. A census of Jewish day schools in the United States 2018-2019. New York, NY: AVI CHAI Foundation.

Bopp, Melissa, Jane A. Peterson, and Benjamin L. Webb. 2012. A comprehensive review of faith-based physical activity interventions. American Journal of Lifestyle Medicine 6 (6): 460-478. 
Borish, Linda J. 1999. "Athletic activities of various kinds": Physical health and sports programs for Jewish American women. Journal of Sport History 26 (2): 240-270.

Bos, Gerrit. 1994. Maimonides on the preservation of health. Journal of the Royal Asiatic Society 4 (2): 213-235.

Bronner, Simon J., and Cindy D. Clark. 2016. Youth cultures in America. Santa Barbara, CA: Greenwood.

Bryfman, David. 2016. Generation now: Understanding and engaging Jewish teens today. New York, NY: The Jewish Education Project.

Centers for Disease Control and Prevention. 2013. Comprehensive school physical activity programs: A guide for schools. Atlanta, GA: U.S. Department of Health and Human Services.

Chatzihidiroglou, Panagiota, Dimitris Chatzopoulos, Georgios Lykesas, and Georgios Doganis. 2018. Dancing effects on preschoolers' sensorimotor synchronization, balance, and movement reaction time. Perceptual Motor Skills 125 (3): 463-477.

Cohen, Steven M., Lawrence A. Hoffman, and Jonathan Ament. 2011. Conservative \& Reform congregations in the United States today: Findings from the FACT-Synagogue 3000 survey of 2010. Stanford, CA: Berman Jewish Policy Archive.

Cohen, Steven, and Eitan Melchior. 2011. The Jewish learning presence in JCC day camps: The current reality and realizing the potential. Stanford, CA: Berman Jewish Policy Archive.

Cohen, Steven M., and Judith Veinstein. 2011. Jewish identity: Who you knew affects how you Jew-the impact of Jewish networks in childhood upon adult Jewish identity. In International handbook of Jewish education, eds. Helena Miller, Lisa D. Grant, and Alex Pomson, 203-218. Heidelberg, Germany: Springer Dordrecht.

Dash Moore, Deborah. 1987. A synagogue center grows in Brooklyn. In The American synagogue: A sanctuary transformed, ed. Jack Wertheimer, 297-326. New York, NY: Cambridge University Press.

Donnelly, Joseph E., Charles H. Hillman, Darla Castelli, Jennifer L. Etnier, Sarah Lee, Phillip Tomporowski, Kate Lambourne, and Amanda N. Szabo-Reed. 2016. Physical activity, fitness, cognitive function, and academic achievement in children: A systematic review. Medicine and Science in Sports and Exercise 48 (6): 1197-1222.

Eisen, George. 1999. Jews and sport: A century of retrospect. Journal of Sport History 26 (2): 225-239.

Foundation for Jewish Camp. 2018a. Highlights from Foundation for Jewish Camp 2018 day camp census. New York, NY: Foundation for Jewish Camp.

Foundation for Jewish Camp. 2018b. Overnight Jewish camp in North America 2018: Highlights from Foundation for Jewish Camp 2018 camp census. New York, NY: Foundation for Jewish Camp.

Frost, Jonathon K., and Norman E. Youngblood. 2014. Online religion and religion online: Reform Judaism and web-based communication. Journal of Media and Religion 13 (2): 49-66.

Gold, Avie. 1991. Purim: Its observance and significance. Rahway, NJ: ArtScroll Mesorah Publications.

Goldfield, Gary S., Alysha Harvey, Kimberly Grattan, and Kristi B. Adamo. 2012. Physical activity promotion in the preschool years: A critical period to intervene. International Journal of Environmental Research and Public Health 9 (4): 1326-1342.

Gurock, Jeffrey S. 2005. Judaism's encounter with American sports. Bloomington, IN: Indiana University Press.

Ingber, Judith B. 2011. Seeing Israeli and Jewish dance. Detroit, MI: Wayne State University Press.

Irie, Ellen, Tina Cheplick, and Sheila Wilcox. 2014. New Jewish specialty camps: From idea to reality. New York, NY: Foundation for Jewish Camp.

Kahan, David. 2007. Gender differences in walking and its correlates in an Orthodox Jewish community: An exploratory study. International Council of HPERD·SD Journal 43(2): 21-29.

Kahan, David. 2002. Religiosity as a determinant of physical activity: The case of Judaism. Quest 54 (2): 97-115.

Kahan, David, Thomas L. McKenzie, Anna O’Brien, Carlos Portillo, Remy Sprague, Emma Marchant, and Nadine Lising. 2020. Physical activity messaging on North American Jewish day school websites. Journal of Jewish Education 86 (3): 271-297.

Kaluski, Dorit Nitzan, Getachew Demem Mazengia, Tal Shimony, Rebecca Goldsmith, and Elliot M. Berry. 2008. Prevalence and determinants of physical activity and lifestyle in relation to obesity among schoolchildren in Israel. Public Health Nutrition 12 (6): 774-782.

Karp, Abraham J. 1987. Overview: The synagogue in America-A historical typology. In The American synagogue: A sanctuary transformed, ed. Jack Wertheimer, 1-36. New York, NY: Cambridge University Press.

Kaufman, David. 1999. Shul with a pool. Hanover, NH: University Press of New England. 
Kaufman, Michael. 2018. Am I my body's keeper? Torah, science, diet, and fitness-for life. Jerusalem: Urim Publications.

Kook, Abraham Isaac, and Bezalel Naor. 1993. Orot. Northvale, NJ: Jason Aronson Inc.

Kotler-Berkowitz, Laurence. 2005. The Jewish education of Jewish children: Formal schooling, early childhood programs, and informal experiences. New York, NY: United Jewish Communities.

Levites, Arielle, and Liat Sayfan. 2019. GenZ now: Understanding and connecting with Jewish teens today. New York, NY: The Jewish Education Project.

McKenzie, Thomas L. 2019. Physical activity within school contexts: The bigger bang theory. Kinesiology Review 8 (1): 48-53.

Mykoff, Nancy. 2009. Summer camping in the United States. https://jwa.org/encyclopedia/article/summer-camping-in-united-states. Accessed 10 October 2020.

Nagel, Ronald. 2008. Pediatric obesity: A challenge for the Orthodox Jewish community. Jewish Action: The Magazine of the Orthodox Union, 5768(3). https://jewishaction.com/health/pedia tric_obesity_a_challenge_for_the_orthodox_jewish_community/. Accessed 13 October 2020.

National Physical Activity Plan Alliance. 2016. National physical activity plan. Columbia, SC: National Physical Activity Plan Alliance.

Nussbaum Cohen, Debra. 2020. Where does the Jewish community center go from here? https:// jewishinsider.com/2020/06/where-does-the-jewish-community-center-movement-go-from-here/. Accessed 19 October 2020.

Partlan, Alisa. 2017. Non $\neq$ equivalent: The state of education in New York City's Hasidic yeshivas. New York, NY: Young Advocates for Fair Education.

Peles, Chagit, Mary Rudolf, Michael Weingarten, and Miriam E. Bentwich. 2018. What can be learned from health-related tensions and disparities in ultra-Orthodox Jewish families? Journal of Religion and Health 57 (3): 1133-1145.

Pew Research Center. 2013. A portrait of Jewish Americans: Findings from a Pew Research Center survey of U.S. Jews. Washington, DC: Pew Research Center.

Physical Activity Council. 2019. 2019 Physical Activity Council's overview report on U.S. participation. Jupiter, FL: Sports Marketing Surveys USA.

Piercy, Katrina L., Richard P. Troiano, Rachel M. Ballard, Susan A. Carlson, Janet E. Fulton, Deborah A. Galuska, Stephanie M. George, and Richard D. Olson. 2018. The physical activity guidelines for Americans. Journal of the American Medical Association 320 (19): 2020-2028.

Purcell, Laura. 2005. Sport readiness in children and youth. Paediatrics and Child Health 10 (6): 343-344.

Rosenberg, Deborah A., Charles Swencionis, and C.J. Segal-Isaacson. 2016. Caloric intake on the Sabbath: A pilot study of factors contributing to obesity in the Orthodox Jewish community. Journal of Religion and Health 55 (5): 1824-1831.

Rosner, Fred, and Ira L. Weg. 1989. Exercise in Judaism. Bulletin of the New York Academy of Medicine 65 (8): 842-850.

Sales, Amy L., and Leonard Saxe. 2004. How goodly are thy tents? Lebanon, NH: University Press of New England.

Samuels, Judith. 2018. Outcomes \& impacts of Jewish day camp. New York, NY: Foundation for Jewish Camp.

Schoenfeld, Stuart. 2020. Jews, Jewish institutions, and the construction of identity in changing American cities and urban neighborhoods. Contemporary Jewry 40 (3): 323-365.

Siegman, Joseph. 2020. Jewish sports legends: The international Jewish sports hall of fame, 5 th ed. Lincoln, NE: University of Nebraska Press.

Silverstein, Alan. 1994. Alternatives to assimilation. Hanover, NH: University Press of New England.

Sukenik, Dovid. 2010. Exercise and therapies on Shabbat. Verapo Yerape: The Journal of Torah and Medicine of the Albert Einstein College of Medicine Synagogue 2. https://www.torahmusings. com/2010/12/new-periodical-verapo-yerape-no-2/. Accessed 19 October 2020.

Tighe, Elizabeth, Raquel M. de Kramer, Daniel Parmer, Daniel Nussbaum, Daniel Kallista, Xajavion Seabrum, and Leonard Saxe. 2019. American Jewish population project: Summary and highlights 2019. Waltham, MA: Brandeis University.

Tristão Parra, Maíra., Gustavo J.M.. Porfirio, Elva M. Arredondo, and Álvaro. N. Atallah. 2018. Physical activity interventions in faith-based organizations: A systematic review. American Journal of Health Promotion 32 (3): 677-690. 
United States Department of Health and Human Services (USDHHS). 2020. Healthy people 2030: Building a healthier future for all. Washington, DC: USDHHS. https://health.gov/healthypeople. Accessed 28 December 2020.

Vogelstein, Ilene. 2008. Early childhood Jewish education- "If not now, when?" In What we know about Jewish education, ed. Roberta L. Goodman and Paul A. Flexner, 373-386. Los Angeles, CA: Torah Aura Productions.

Wechsler, Bob. 2008. Day by day in Jewish sports history. Jersey City, NJ: KTAV Publishing House Inc.

Weingarten, Michael A. 2007. Prevention in halakhah. Israel Medical Association Journal 9 (3): 180-182.

Wertheimer, Jack. 2008. A census of Jewish supplementary schools in the United States 2006-2007. New York: AVI CHAI Foundation.

Wertheimer, Jack. 1996. Conservative synagogues and their members. New York, NY: Jewish Theological Seminary.

Wertheimer, Jack, ed. 1987a. The American synagogue: A sanctuary transformed. New York, NY: Cambridge University Press.

Wertheimer, Jack. 1987b. The Conservative synagogue. In The American synagogue: A sanctuary transformed, ed. Jack Wertheimer, 111-152. New York, NY: Cambridge University Press.

Whitehead-Bust, Michael. 2010. Current trends in Jewish teen participation with out-of-school activities: A survey and analysis of relevant research. https://rcfdenver.org/wp-content/uploads/2017/06/Curre ntTrendsinJewishTeenParticipation0210.pdf. Accessed 22 October 2020.

Woocher, Meredith. 2015. Insights and perspectives from Jewish teens: A report on research conducted for the National Incubator for Community-Based Jewish Teen Initiatives. New York, NY: The Jewish Education Project.

Publisher's Note Springer Nature remains neutral with regard to jurisdictional claims in published maps and institutional affiliations.

David Kahan is Associate Director and Professor in the School of Exercise and Nutritional Sciences, San Diego State University.

Thomas L. McKenzie is Professor Emeritus in the School of Exercise and Nutritional Sciences, San Diego State University.

Maya Satnick is an undergraduate major in the School of Exercise and Nutritional Sciences, San Diego State University.

\section{Authors and Affiliations}

\section{David Kahan $^{1}$ D $\cdot$ Thomas L. McKenzie $^{1}$ iD $\cdot$ Maya Satnick ${ }^{1}$}

David Kahan

dkahan@sdsu.edu

Thomas L. McKenzie

tmckenzi@sdsu.edu

Maya Satnick

mayasatnick@yahoo.com

1 School of Exercise and Nutritional Sciences, San Diego State University, ENS Building 315, 5500 Campanile Drive, San Diego, CA 92182-7251, USA 